\title{
Без расчета на пенсию 1
}

ю.П. вОРОНОВ, кандидат экономических наук, Институт экономики и организации промышленного производства СО РАН, Новосибирск

Аннотация. В статье рассматриваются перспективы использования в России зарубежного опыта пожизненного найма. Проанализированы для примера его японский и европейский варианты. Отмечается, что пожизненный наем существует в определенной благоприятной для него среде, предполагающей, в частности, большое пособие при выходе на пенсию, учет при назначении зарплаты наличия у работника иждивенцев, принятие всех новых работников на одинаковую зарплату. С учетом изменений, происшедших после первой публикации автора на эту тему (см. ЭКО № 3/2011), он приходит к выводу, что введение полномасштабного пожизненного найма в России в настоящее время не целесообразно, но отдельные его элементы кажутся вполне уместными. В частности, представляется возможным и даже желательным введение пожизненного найма для отдельных категорий преподавателей российских вузов. Помимо прочего, это может снизить социальную напряженность в отношении повышения пенсионного возраста, поскольку для части работников и компаний станет привлекательной система пожизненного найма. По мнению автора, нужно изменить роль Пенсионного фонда России, исключив из его компетенции назначение, начисление и выплату пенсий государственным служащим.

Ключевые слова: Пенсионный фонд; государственное казначейство; пожизненный наем; японский опыт; европейский опыт; система образования; государственные корпорации; железные дороги; прием на работу; пособие при выходе на пенсию

Когда восемь лет назад автор впервые обратился к теме пожизненного найма, считалось, что с отечественной пенсионной системой все в порядке [Воронов, Тюрин, 2011]. Тогда не только в научной литературе, но и во многих СМИ спокойно обсуждали повышение пенсионного возраста во Франции и Эстонии, не предполагая, что очень скоро это станет реальностью и в России. И если в то время рассуждения о перспективах пожизненного найма в РФ воспринимались почти как игра ума, то сейчас, после законодательного повышения пенсионного возраста, этот вопрос стал актуальным и в практическом плане.

В митингах, спорах и голосованиях прошла почти незамеченной одна радикальная инициатива. Борис Юрьевич Титов, уполномоченный при Президенте России по правам предпринимателей, предложил ликвидировать Пенсионный фонд России

\footnotetext{
${ }^{1}$ Статья подготовлена в рамках плана НИР ИЭОПП СО РАН, проект ХІ.170.1.2. «Формирование основ теории инновационной экономики: операциональные определения, измерения, модели, научно-технологические прогнозы и программы», № AAAA-A17-117022250128-5.
} 
(ПФР) и передать его функции Федеральному казначейству. По его мнению, современные информационные технологии позволяют обойтись без таких громоздких и не вполне прозрачных организаций, как ПФР: «...это уже лишняя организация, которая неэффективно тянет деньги, и поэтому можно было бы от нее полностью отказаться» ${ }^{2}$. Он сослался также на случаи, когда из-за нестыковок информации от Пенсионного фонда и ФНС налоговые органы выставляли предпринимателям повторные счета.

При этом современная система обработки информации, созданная в Казначействе, позволяет эффективно контролировать большинство связанных с государством финансовых потоков и в принципе способна справиться с функциями, выполняемыми сейчас ПФР. В других условиях (если бы общее внимание не было привлечено к повышению пенсионного возраста) тема осмысленности существования Пенсионного фонда как особой структуры (высокозатратной и малоэффективной), очевидно, вызвало бы бо́льший резонанс в обществе. Мне это предложение кажется, в принципе, справедливым, хотя его и сложно реализовать через одно мероприятие.

Если придерживаться данной концепции, то позиция ПФР наиболее слаба в отношении страховых пенсий государственных служащих. Фактически необходимые для этого средства передаются в фонд из Казначейства. При сравнении же сумм выплат, получаемых работниками в течение жизни после выхода на пенсию, в России и ряде западных стран (табл. 1) существование ПФР кажется еще более бессмысленным.

Грубые прикидки для 25-летнего в среднем трудового стажа (срока накопления в ПФР) дают следующую минимальную оценку при средней официальной зарплате (табл. 2).

Идея накопительной пенсионной системы состоит в том, что отчисления в Пенсионный фонд будут инвестироваться и приносить доход. Предположим, что их будут размещать на банковском депозите, где реальная ставка равна 2\% (при номинальной ставке депозита, скажем, 7\%, и инфляции не менее 5\%). Тем самым мы исключаем из расчетов инфляцию, что позволяет вести расчеты в номинальных зарплатах и пенсиях.

${ }^{2}$ Титов предложил упразднить Пенсионный фонд (редакционная статья) // Ведомости 05.07.2018. URL: https://www.vedomosti.ru/economics/news/2018/07/05/774768-titov (дата обращения: 01.07. 2019). 
Таблица 1. Сравнение совокупных выплат пенсионерам по 10 странам, по состоянию на 2017 г.

\begin{tabular}{|l|c|c|c|c|c|c|}
\hline \multicolumn{1}{|c|}{ Страна } & $\begin{array}{c}\text { Возраст } \\
\text { выхода } \\
\text { на пен- } \\
\text { сию, лет }\end{array}$ & $\begin{array}{c}\text { Средняя } \\
\text { продолжи- } \\
\text { тельность } \\
\text { жизни, лет }\end{array}$ & $\begin{array}{c}\text { Раз- } \\
\text { ница, } \\
\text { лет }\end{array}$ & $\begin{array}{c}\text { Средне- } \\
\text { месячная } \\
\text { пенсия*, } \\
\text { тыс. руб. }\end{array}$ & $\begin{array}{c}\text { Сумма } \\
\text { выплат } \\
\text { до смерти, } \\
\text { тыс. руб. }\end{array}$ & $\begin{array}{c}\text { Превышение } \\
\text { над россий- } \\
\text { ской суммой } \\
\text { выплат, раз }\end{array}$ \\
\hline Россия & $60,0^{\star \star}$ & 72,0 & 12,0 & 14,0 & 2016 & 1 \\
\hline Япония & 70,0 & 82,0 & 12,0 & 47,7 & 6869 & 3,4 \\
\hline $\begin{array}{l}\text { Великобрита- } \\
\text { ния }\end{array}$ & 65,0 & 79,0 & 14,0 & 53,5 & 8988 & 4,5 \\
\hline Германия & 65,5 & 79,0 & 13,5 & 62,0 & 10044 & 5,0 \\
\hline Испания & 65,0 & 80,0 & 15,0 & 58,0 & 10440 & 5,2 \\
\hline США & 67,0 & 78,0 & 11,0 & 79,0 & 10428 & 5,2 \\
\hline Франция & 67,0 & 81,0 & 14,0 & 63,5 & 10668 & 5,3 \\
\hline Норвегия & 67,0 & 79,0 & 12,0 & 136,0 & 19584 & 9,7 \\
\hline Швейцария & 65,0 & 80,0 & 15,0 & 118,5 & 21330 & 10,6 \\
\hline Дания & 67,0 & 78,0 & 11,0 & 222,0 & 29304 & 14,5 \\
\hline
\end{tabular}

Примечание: * Рассчитано по курсу Банка России на 25.12.2017 и кросс-курсам. ** Результат пенсионной реформы обсуждается далее.

Источник. Составлено по данным URL: https://radarmedia.net/rossijskiepensii-sravnili-s-mirovymi/?utm_medium =referral\&utm_source=lentainform\&utm campaign=radarmedia.net\&utm_term $=1274680 \& u t m \_c o n t e n t=7007736$

\section{Таблица 2. Расчеты накопленных налоговых отчислений} c $1994^{\star}$ r. по 2018 r.

\begin{tabular}{|c|c|c|c|c|c|c|}
\hline Год & $\begin{array}{c}\text { Среднеме- } \\
\text { сячная но- } \\
\text { минальная** } \\
\text { зарплата, } \\
\text { руб. }\end{array}$ & $\begin{array}{c}\text { Годовая } \\
\text { номи- } \\
\text { нальная } \\
\text { зарпла- } \\
\text { та, руб. }\end{array}$ & $\begin{array}{c}\text { Коэфф. } \\
\text { пересчета } \\
\text { по индексу } \\
\text { цен (2018 г. } \\
\mathbf{2 1 , 0 0 ) * * *}\end{array}$ & $\begin{array}{c}\text { Годовая } \\
\text { зарплата } \\
\text { в ценах } \\
\mathbf{2 0 1 8} \text { г., } \\
\text { тыс. руб. }\end{array}$ & $\begin{array}{c}\text { Отчисления } \\
\text { в год исходя } \\
\text { из ставки } \\
\mathbf{2 2 \% , ~ т ы с . ~} \\
\text { руб. }\end{array}$ & $\begin{array}{c}\text { Накопленные } \\
\text { отчисления } \\
\text { с приростом } \\
\text { в 2\% в год, } \\
\text { тыс. руб. }\end{array}$ \\
\hline 1994 & 220,4 & 2644,8 & 49,96 & 132,14 & 29,07 & 47,69 \\
\hline 1995 & 472,4 & 5668,8 & 21,60 & 122,45 & 26,94 & 43,33 \\
\hline 1996 & 790,2 & 9482,4 & 17,73 & 168,15 & 36,99 & 58,33 \\
\hline 1997 & 950,2 & 11402,4 & 15,97 & 182,11 & 40,06 & 61,94 \\
\hline 1998 & 1051 & 12612 & 8,66 & 109,22 & 24,03 & 36,42 \\
\hline 1999 & 1523 & 18276 & 6,34 & 115,92 & 25,50 & 37,90 \\
\hline 2000 & 2223 & 26676 & 5,28 & 140,79 & 30,97 & 45,12 \\
\hline 2001 & 3240 & 38880 & 4,45 & 173,05 & 38,07 & 54,37 \\
\hline 2002 & 4360 & 52320 & 3,87 & 202,39 & 44,53 & 62,35 \\
\hline 2003 & 5499 & 65988 & 3,45 & 227,93 & 50,14 & 68,84 \\
\hline 2004 & 6740 & 80880 & 3,09 & 250,04 & 55,01 & 74,03 \\
\hline 2005 & 8555 & 102660 & 2,79 & 286,13 & 62,95 & 83,06 \\
\hline 2006 & 10634 & 127608 & 2,56 & 326,29 & 71,78 & 92,86 \\
\hline 2007 & 13593 & 163116 & 2,29 & 372,83 & 82,02 & 104,02 \\
\hline
\end{tabular}


Окончание табл. 2

\begin{tabular}{|c|c|c|c|c|c|c|}
\hline Год & $\begin{array}{c}\text { Среднеме- } \\
\text { сячная но- } \\
\text { минальная** } \\
\begin{array}{c}\text { зарплата, } \\
\text { руб. }\end{array}\end{array}$ & $\begin{array}{c}\text { Годовая } \\
\text { номи- } \\
\text { нальная } \\
\text { зарпла- } \\
\text { та, руб. }\end{array}$ & $\begin{array}{c}\text { Коэфф. } \\
\text { пересчета } \\
\text { по индексу } \\
\text { цен (2018 г. } \\
\mathbf{2 1 , 0 0 ) * * *}\end{array}$ & $\begin{array}{c}\text { Годовая } \\
\text { зарплата } \\
\text { в ценах } \\
\mathbf{2 0 1 8} \text { г., } \\
\text { тыс. руб. }\end{array}$ & $\begin{array}{c}\text { Отчисления } \\
\text { в год исходя } \\
\text { из ставки } \\
\mathbf{2 2 \% , ~ т ы с . ~} \\
\text { руб. }\end{array}$ & $\begin{array}{c}\text { Накопленные } \\
\text { отчисления } \\
\text { с приростом } \\
\text { в 2\% в год, } \\
\text { тыс. руб. }\end{array}$ \\
\hline 2008 & 17290 & 207480 & 2,02 & 418,64 & 92,10 & 114,51 \\
\hline 2009 & 18638 & 223656 & 1,85 & 414,78 & 91,25 & 111,23 \\
\hline 2010 & 20952 & 251424 & 1,70 & 428,64 & 94,30 & 112,70 \\
\hline 2011 & 23369 & 280428 & 1,61 & 450,60 & 99,13 & 116,15 \\
\hline 2012 & 26629 & 319548 & 1,51 & 481,80 & 106,00 & 121,76 \\
\hline 2013 & 29792 & 357504 & 1,42 & 506,28 & 111,38 & 125,43 \\
\hline 2014 & 32495 & 389940 & 1,27 & 495,92 & 109,10 & 120,46 \\
\hline 2015 & 34030 & 408360 & 1,13 & 459,97 & 101,19 & 109,53 \\
\hline 2016 & 36709 & 440508 & 1,07 & 470,80 & 103,58 & 109,92 \\
\hline 2017 & 39167 & 470004 & 1,04 & 490,03 & 107,81 & 112,16 \\
\hline 2018 & 43724 & 524688 & 1,00 & 524,69 & 115,43 & 117,74 \\
\hline & Итого & 4591754 & & & 1749,34 & 2141,86 \\
\hline
\end{tabular}

Примечания: * 1994 г. в расчетах не участвует, он нужен только как отправная база для расчетов.

** URL: http://www.gks.ru/wps/wcm/connect/rosstat_main/rosstat/ru/statistics/ wages/

*** URL: http://www.gks.ru/free_doc/new_site/prices/potr/tab-potr1.htm

Средний размер ежемесячной пенсии в 2018 г. составил 13700 руб., или 164,4 тыс. руб. на одного пенсионера в год Средняя продолжительность жизни на 2018 г. равна 72,7 года. Таким образом, если считать, что средний возраст выхода на пенсию составляет 61,7 года ${ }^{4}$, то выплаты продолжаются, в среднем 11 лет, а сумма выплат до смерти (без дисконтирования) составит 1,8 млн руб.

В итоге после смерти пенсионера на счету ПФР остается накопленных им примерно 2,1-1,8 = 0,3 млн руб.

Оговорюсь, что при такой оценке не учитываются следующие факторы:

- многие плательщики отчислений в ПФР не доживают до пенсии, их остаток на счетах ПФР не учитывается при выплате премий дожившим до пенсии;

- фактический стаж у многих трудящихся больше расчетного (например, у автора - вдвое);

\footnotetext{
${ }^{3}$ URL: https://promdevelop.ru/rabota/razmery-srednej-pensii-po-rossii-v-2018-godu/

${ }^{4}$ Такая цифра получается, если учитывать, что до пенсии доживает в два раза больше женщин, чем мужчин.
} 
- работающие пенсионеры продолжают платить в ПФР;

- пенсия не выплачивается сразу за 11 последующих лет жизни на пенсии, и на остаток продолжают начисляться проценты (как минимум, 2\% годовых) - вплоть до смерти получателя; при этом сумма, с которой ПФР получает (или может получить) доход, начинает для неработающего пенсионера уменьшаться;

- правильнее было бы считать не среднюю продолжительность жизни, а возраст дожития для всех выходящих на пенсию (отдельно по мужчинам и женщинам).

При учете этих пяти факторов невыплаченный пенсионеру остаток будет (при более корректном расчете) еще больше, но порядок цифр в целом понятен. Кому достается остаток? В этом вопросе есть правовая лакуна, хотя, на взгляд автора, логично было бы отдавать его наследникам.

Впрочем, есть еще один важный неучтенный фактор. Неизвестно, как и где работают деньги пенсионеров, поскольку нет требования к ПФР об обязательной отчетности перед клиентами (будущими и нынешними пенсионерами). Эта проблема служит постоянным предметом тревог общественных организаций ${ }^{5}$. Она же резко отличает Россию от большинства других стран, где государственные организации, включая пенсионные фонды, обязаны подавать пример прозрачности. Образцом можно считать Пенсионный фонд Тайваня, который публично отчитывается по своим вложениям (допускается размещение средств в 50 странах мира, но только в долгосрочные проекты с низким риском).

Из-за отсутствия данных о работе ПФР мы сегодня не можем подключиться к сравнительным исследованиям о деятельности пенсионных фондов других стран мира, которые ведутся многими исследователями [Bodie, Merton, 2002]. Если деньги ПФР вкладываются не только в депозиты, то и накопленная сумма отчислений должна ежегодно увеличиваться не на $2 \%$, а больше.

По мнению автора, России следует резко повысить прозрачность деятельности ПФР. Но, с учетом сложности этой задачи, одним из возможных выходов может стать введение системы пожизненного найма.

${ }^{5}$ Инициатива № 24Ф46433, URL: https://www.roi.ru/46433/ 


\section{Пожизненный наем в Японии как элемент трудовых отношений}

Пожизненный наем связывается обычно с японским опытом. Министерство труда Японии определяет его как «практику компаний нанимать основных работников напрямую из университетов, планируя их будущее обучение и развитие в рамках компании или корпоративной группы вплоть до достижения ими пенсионного возраста, гарантируя им постоянную работу... кроме непредвиденных случаев» [Куликов, 2000]. На основании этого определения в категории пожизненно нанятых смешаны две подгруппы: основная - те, кто работает в одной компании до пенсии, и вторая - кто работает, никогда не получая пенсии, до самой смерти.

Считается, что пожизненный наем дает, по меньшей мере, пять преимуществ в сравнении с наймом на срок:

1) ориентацию персонала на долгосрочные (перспективные) задачи как для себя лично, так и для компании в целом;

2) гарантию, что сотрудников высокой квалификации не переманит конкурент, поскольку уходя работник теряет право на пожизненную занятость;

3) обучение и повышение квалификации внутри фирмы будут гарантированно окупаться, а значит, в это можно больше вкладываться;

4) снижение потребности в постоянном контроле результатов работы;

5) работники готовы трудиться с полной отдачей не только за зарплату, а за гарантированную карьеру и социальную защищенность ${ }^{6}$.

В частности, руководство компании Тoyota полагает, что пожизненный наем обеспечивает высокий уровень квалификации и лояльность работников [Abegglen, 2006].

В то же время многие исследователи отмечают, что пожизненный наем не лишен недостатков: он снижает трудовую мобильность, а иногда - и трудовую мотивацию. В настоящее время преданность работников фирме и упорный труд не всегда тесно связаны друг с другом [Морита, 2005]. Низкая эффективность пожилых работников, фактическое содержание в штате лишнего

${ }^{6}$ Tucker, K. Advantages of Permanent Employment, Work-Chron.com, http://work.chron. com/advantages-permanent-employment-8921.html. Accessed 24 July 2019. 
персонала также относятся к таким недостаткам. По этим причинам в Японии некоторые крупные корпорации отходят от пожизненного найма в сторону более изощренных систем занятости и оплаты труда [Haak, 2005].

Широкое распространение практика пожизненного найма в этой стране получила после Второй мировой войны, когда спрос на квалифицированную рабочую силу стал опережать ее предложение. Можно провести определенную аналогию с ситуацией, сложившейся в СССР во время индустриализации 1920-1930-х гг. В определенной мере советское руководство использовало схожие методы регулирования рынка труда, сформировав категорию «номенклатуры», или «кадрового резерва». Фактически это была аналогия гарантии пожизненного найма в пределах страны в целом или отдельного ее региона, хотя касалась она относительно небольшого числа работников.

Систему пожизненного найма нельзя рассматривать в отрыве от сопутствующих ей обстоятельств и процессов, которые, возможно, не менее важны, чем сам пожизненный наем.

В Японии выделяют четыре категории работников, в отношении которых применяется разная стратегия оплаты труда: первая - молодые и холостые (незамужние) до 30 лет-умеренный стимулирующий рост зарплаты; вторая - женатые (замужние) до 40 лет и при рождении детей - заметное повышение зарплаты; третья (от 40 до 50 лет) - медленный рост зарплаты, индексирование с учетом инфляции и, наконец, предпенсионный возраст (после пятидесяти лет), слабое индексирование зарплаты.

Введение категории «предпенсионный возраст» в контекст российской пенсионной реформы представляется прямым заимствованием японского опыта. Следующий шаг, какой, несомненно, будет сделан в самое ближайшее время - заключение срочных трудовых договоров (на 1-5 лет).

В настоящее время в России активно используется практика приема работников на испытательный срок (не более двух месяцев), которая регулируется Ст. 70 Трудового кодекса РФ «Испытание при приеме на работу». При этом для заключения срочного договора требуются специальные основания. Согласно Трудовому кодексу РФ, «трудовой договор, заключенный на определенный срок при отсутствии достаточных к тому оснований, установленных судом, считается заключенным на неопределенный срок; 
запрещается заключение срочных трудовых договоров в целях уклонения от предоставления прав и гарантий, предусмотренных для работников, с которыми заключается трудовой договор на неопределенный срок» ${ }^{7}$.

К числу условий, которые ТК считает достаточными для заключения срочного договора, относится, например, наем лиц, поступающих «на работу к работодателям - субъектам малого предпринимательства (включая индивидуальных предпринимателей), численность работников которых не превышает 35 человек» ${ }^{8}$.

В Японии срочный трудовой договор (обычно на год) заключается без обоснований. Считается, что эта практика повышает качество рабочей силы и служит фильтром для вхождения работников в систему пожизненного найма. Сходную функцию выполняет и система неполной занятости, получающая все большее распространение после кризиса 1990-х годов. Почти 40\% трудящихся в Японии сейчас имеют неполную занятость, тогда как в начале 1990-х таких было менее 20\% [Fahey, 2018].

В большинстве стран мира частные компании предлагают своим сотрудникам социальные пакеты, которые могут быть нормированы или нет на национальном уровне 9 . Как правило, у тех, кто включен в систему пожизненного найма, этот пакет всегда больше, чем у других. Фактически такая льгота - это обязательный элемент данной системы. Кроме того, нужно учесть, что при выходе на пенсию работник в Японии, не включенный в систему пожизненного найма, получает единовременное выходное пособие в сумме нескольких годовых окладов из фонда заработной платы. Хотя нанятые пожизненно получат существенно больше, но разрыв между теми, кто уходит на пенсию и занят пожизненно, психологически сокращается.

Пожизненный наем получил распространение в японской хозяйственной практике еще и потому, что исторически культура трудовых отношений не предполагала сокращение персонала при ухудшении положения компании на рынке. Такое поведение считается неэтичным даже в отношении тех работников, на каких система пожизненного найма не распространяется, и сильно

\footnotetext{
${ }^{7}$ Статья 58 ТК РФ.

8 Часть 2 Статьи 59 ТК РФ.

${ }^{9}$ Tucker, K. Advantages of Permanent Employment. URL: https://work.chron.com/ advantages-permanent-employment-8921.html (дата обращения: 01.07.2019).
} 
осуждается. До сих пор в СМИ обсуждается увольнение 13\% работников компании «Мацусита», которое случилось в 1950 г, и было единственным в ее истории. Однако временное понижение зарплаты и частичное свертывание социального пакета в случае финансовых трудностей у компании воспринимаются с пониманием.

Неотъемлемыми сопутствующими процессами системы пожизненного найма в японском варианте являются большая доля временных работников, работающих по срочным договорам, отказ от индивидуальных премий, и, по возможности, - от увольнений, прием всех новых работников на одинаковую зарплату и в дальнейшем, при повышении заработной платы, учет семейных обстоятельств, большое выходное пособие при достижении пенсионного возраста.

Специфически японское решение этих вопросов позволяет смягчить проблему повышения пенсионного возраста. Как известно, в Японии в 2018 г. повысили пенсионный возраст для мужчин и женщин до 70 лет. И в стране, где демонстрации трудящихся - довольно обычное явление, - не было волнений и публичного выражения массового недовольства.

Неправильно полагать, что пожизненный наем всегда действует в рамках отдельной компании. Возможно вступление отдельных из них в своеобразные пулы, формирующие «закрытый», или «внутренний» рынок труда. В таких случаях допускается переход работника из одной компании пула в другую по взаимной предварительной договоренности работодателей [Япония.., 1990].

\section{Пожизненный наем помимо Японии}

Японский опыт пожизненного найма не уникален: «...в любой стране люди хотят стабильности... поэтому даже в США огромные компании... фактически применяют систему пожизненного найма» [Кавато, 2006]. В той или иной форме элементы пожизненного найма используют компании Boeing, Caterpillar Tractor, Dana Corporation, Delta Airlines, Digital Equipment, Eastman Kodak, Emerson Electric, Hewlett-Packard, IBM, Marriott, McDonald's, Minnesota Mining \& Manufacturing Procter \& Gamble, Texas Instruments. В последнее время во многих странах обсуждается проблема дополнения (или замены) пенсионного обеспечения через заимствование японского опыта пожизненного найма [Журавлев и др., 2007]. 
В Европе пожизненный наем впервые стал внедряться на родине «пенсионной идеи»-в Германии. Считается, что немецкая система сделана по образцу японской, тем не менее различия между ними весьма существенны благодаря совершенно иной предыстории.

В Германии с давних пор законодательно допускаются объединения работодателей и наемных работников, которые совместно (без посредников в лице профсоюзов) определяют размеры заработной платы и условия труда. После поражения во Второй мировой войне данный элемент хозяйственной практики (связанный в глазах победителей с хозяйственной системой гитлеровской Германии) так и не был полностью устранен. И современная система пожизненного найма переняла многие его черты.

В сентябре 2010 г. фирма «Сименс» ввела систему пожизненного найма для 128 тыс. из 250 тыс. своих работников. Сделано это было как торжественное обязательство руководства фирмы, что все работники, включенные в программу пожизненного найма, могут быть уволены только по собственному желанию. Никаких сокращений штатов или досрочных уходов на пенсию.

\section{Пожизненный наем и Россия}

В России не применяется понятие «пожизненный наем», однако для многих российских работников характерна продолжительная работа на одном предприятии, иногда даже в течение всей трудовой деятельности.

В российских научно-исследовательских организациях, особенно в системе РАН, система пожизненного найма фактически уже сложилась. Ученые с большими заслугами перед наукой не уходят на пенсию, а получают статус научного руководителя, советника или главного научного сотрудника. Их лишают только административных функций.

В Японии, кстати, тоже существует похожая категория заслуженных людей, которым платят просто за присутствие на рабочем месте. Их называют мадогивадзоку - «сидящие у окна», и это, собственно, их основная функция в компании, за которую они получают зарплату. Заработок, понятно, ниже, чем в среднем у тех, кто помоложе и еще трудится, но все же больше вероятной пенсии. К тому же предполагается, что рядовые сотрудники 
могут обращаться к «сидящим» за консультациями или советами, которые нередко приносят ощутимую пользу.

Есть и другие примеры успешного «приживления» пожизненного найма в России. Например, в российской страховой (перестраховочной) компании «Москва Ре» эта система действует с самого основания (1996 г.). Для сотрудников это означает, что из компании их не могут уволить за проколы в работе. Такой порядок был введен при участии одного из создателей компании Кахи Бендукидзе (1956-2014), российского предпринимателя, профессора МГУ и министра экономики Грузии [Карасюк, 2011].

Общепризнано, что система пожизненного найма хорошо развивается при высоких темпах экономического роста. По этому критерию перспективы внедрения ее в России в данный момент, безусловно, не представляются наилучшими. Но есть и другой фактор, который, напротив, стимулирует введение пожизненного найма. Это - усугубляющийся дефицит квалифицированных работников.

Особое место в перспективах внедрения системы пожизненного найма в России занимает государственная служба. Государственные учреждения более надежны, чем частные предприятия, здесь проще официально утвердить единые нормы пожизненного найма в соответствии с принятыми юридическими процедурами. К тому же в стране уже есть опыт дифференцированного назначения пенсий для государственных служащих.

Правовой статус государственных гражданских служащих как получателей пенсии определяется в зависимости от вида госслужбы. Пенсионное обеспечение за выслугу лет федеральных гражданских госслужащих регулируется Ф3 № 166, а гражданских госслужащих субъектов РФ - законами регионального уровня. В системе пенсионных отношений федеральные государственные гражданские служащие выступают не как единый, а как разноплановый специальный субъект. Среди них можно выделить четыре основные подгруппы, в зависимости от 1) продолжительности требуемого стажа; 2) причины увольнения; 3) замещаемой должности; 4) совокупности условий назначения пенсии за выслугу лет. Кроме того, «с повышением пенсионного возраста приобрел значение и такой критерий, как срок назначения пенсии за выслугу лет: а) по достижении повышенного пенсионного возраста или б) по достижении общего пенсионного возраста для назначения страховой пенсии по старости» [Миронова, 2018. С. 108]. 
Из бизнес-структур наиболее подготовленной организацией в России для внедрения системы пожизненного найма представляется РЖД. Сегодня пенсионеры-железнодорожники получают выплаты через Пенсионный фонд РФ, но работники могут принять участие также в негосударственном пенсионном страховании через фонд «Благосостояние». В 1956 г. у некоторых категорий железнодорожников (перечень закрыт, но довольно обширен) появилось право выходить на пенсию раньше срока при условии выработки обязательного стажа.

По нашему мнению, именно на существующую систему пенсионного обеспечения российских железнодорожников могла бы постепенно накладываться система пожизненного найма, первоначально дополняя, а затем и замещая ее.

Наконец, применительно к российской специфике необходимо обратить внимание еще на один момент. В Японии, как правило, коллектив той или иной компании воспринимается как большая семья. Руководители нередко общаются с сотрудниками во внерабочее время, иногда приглашают на чай или даже на кружку пива, регулярно интересуются личными делами, нередко помогают, используя личные связи. Поэтому обязательства компании перед работником (в том числе относительно условий найма), по сути, воспринимаются как личные обязательства ее руководителя. И если эти обязательства будут нарушены, выводы относительно руководителя будут сделаны не по формальным причинам, не в отношении конкретного случая, а в целом о его деятельности и моральном облике.

Именно этот аспект системы пожизненного найма, очевидно, очень сложно будет перенести в Россию. Руководители разного уровня не привыкли считаться с общими оценками их стиля руководства, предпочитая отвечать лишь за совершенно конкретные дела. Вероятно, если будет принято решение даже о частичном внедрении в России системы пожизненного найма, эта специфика потребует разработки и принятия специальных законодательных норм, которые бы определяли правила действий руководства с учетом форм собственности (в Японии нужды в этом нет, поскольку порядок определяется традициями и сложившейся хозяйственной практикой). Вместе с тем в случае частичной (отраслевой или региональной) реализации принципов пожизненного найма будет достаточно принятия локальных или отраслевых нормативных актов. 


\section{Система подготовки кадров как экспериментальная площадка}

Как и в любом деле, при внедрении системы пожизненного найма лучше действовать постепенно. Например, выделив для начала «пилотный» сегмент деятельности, на который данная система может распространиться в первую очередь. По мнению автора, таким сегментом в РФ может стать сфера высшего образования, которая в наибольшей степени подготовлена и к введению пожизненного найма, и к более широкому распространению системы срочных договоров.

Наличие подобного опыта в высшем образовании зарубежных стран значительно упрощает задачу. Так, во многих университетах США и стран Британского содружества у профессуры есть возможность заключить пожизненный контракт (tenure), лишающий руководство права увольнения данного преподавателя. Это дает стимул преподавателям работать на репутацию вуза и защищает от увольнения при конфликте с администрацией или увлечению тематикой, в оценке важности которой ученый расходится с руководством. В США на страже интересов таких преподавателей стоит еще и Американская ассоциация профессоров университетов (American Association of University Professors) - лишнее свидетельство того, что для введения системы пожизненного найма требуется сформировать определенную, благоприятную для нее среду ${ }^{10}$. Численность и доля таких преподавателей повышают репутацию и рейтинг учебного заведения.

Право на пожизненное занятие должности было в 1980-х годах ограничено в Великобритании, а в Новой Зеландии и других странах Содружества - формально заменено долгосрочными договорами, превышающими среднее время дожития; его не существует в Австралии и во многих европейских странах. Более того, в большинстве европейских университетов для аспирантов и молодых исследователей преподавание запрещено независимо от наличия/ отсутствия ученой степени. В Германии преподавание формально разрешается только профессорам и ограниченному количеству штатных сотрудников, но на деле значительную часть преподавательской работы проводят студенты и аспиранты, работающие

\footnotetext{
${ }^{10}$ URL: https://www.aaup.org/report/recommended-institutional-regulations-academicfreedom-and-tenure
} 
в лабораториях, возглавляемых профессорами, а также внештатные сотрудники. Во французской науке пожизненный наём - распространенное явление, начиная с молодых ученых.

В России формально действует система контрактного найма, но трудовой договор продлевается в случае успешной переаттестации персонала каждые 3-5 лет, вследствие чего должность, как правило, может быть занята пожизненно. Тем не менее условия найма профессорско-преподавательского состава и научных сотрудников не гарантируют, например, от увольнения по сокращению штатов.

На наш взгляд, учебным заведениям, входящим в отраслевые структуры, полезно использовать накопленный зарубежный опыт. С высокой вероятностью, это будет комбинация опыта разных стран.

\section{Выводы}

Итак, в случае внедрения пожизненного найма в России необходимо учитывать следующие обстоятельства и рекомендации.

1. Введение полномасштабного пожизненного найма в России в настоящее время не имеет перспектив, но вполне могут быть введены некоторые его элементы.

2. Пожизненный наем не существует сам по себе, для его успешного функционирования необходимо внедрение дополнительных мер, относящихся к повышению лояльности работников, а именно:

- значимым элементом обеспечения лояльности является учет семейных обстоятельств при назначении зарплаты;

- должна быть распространена практика приема всех новых сотрудников на одну и ту же зарплату;

- постепенно следует отказываться от индивидуальных премий; все премии должны выдаваться коллективам, пусть даже из двух человек;

- должна быть расширена система срочных трудовых договоров.

3. Вполне возможно и желательно введение пожизненного найма для отдельных категорий преподавателей российских вузов.

4. Наиболее перспективным направлением является расширение системы пожизненного найма на российских железных дорогах.

5. Государственные служащие должны получать пенсию из Казначейства, а не из Пенсионного фонда. 


\section{Литература}

Воронов Ю.П., Тюрин А.О. Реален ли в России пожизненный наем? // ЭКО. 2011. № 3. С. 92.

Журавлев П.В., Кулапов М.Н., Сухарев С.А. Мировой опыт в управлении персоналом. Обзор зарубежных источников. Екатеринбург: Деловая книга, 2007.

Кавато А. Японская экономика: прошлое, настоящее, будущее // Япония сегодня, 2006. № 2. С. 5.

Карасюк Е. Презумпция невиновности «Москва Ре» // Секрет фирмы. 2011. № 1-2. С. $305-306$.

Куликов Г.В. Японский менеджмент и теория международной конкурентоспособности. М.: Экономика, 2000. С. 144.

Миронова T.К. Пенсии за выслугу лет и их социально-правовая оценка с позиций отраслевой науки и конституционного правосудия, Matters of Russian and International Law. 2018, Vol. 8, Is. 8A, Pp. 103-113.

Морита А. Сделано в Японии / Пер. с англ. М: Альпина Бизнес Букс, 2005. C. 133.

Япония: смена модели экономического роста / Отв. ред. И.П. Лебедева, А.И. Крацевич. М.: Наука. Главная редакция восточной литературы, 1990. C. 101.

Abegglen J. C. 21st century Japanese management: new systems, lasting values. N.Y.: Palgrave Macmillan, 2006. P. 77-80.

Bodie, Z., Merton, R.C. International Pension Swaps. Journal of Pension Economics and Finance, 2002. March. Pp. 77-83.

Fahey R. Japan by the Numbers: Permanent Employment, Tokyo Review, 2018, April, 6.

Haak R. Japanese Production Management: Organizational Learning at the Confluence of Knowledge Transfer, Technology Development and Work Organization // Japanese management: the search for a new balance between continuity and change / edited by R. Haak and M. Pudelko. N.Y.: Palgrave Macmillan, 2005. P. 213-237.

Статья поступила 06.05.2019.

Для цитирования: Воронов Ю. П. Без расчета на пенсию // ЭКО. 2019. № 11. C. 116-131. DOI: 10.30680/ECO0131-7652-2019-11-116-131.

\section{Summary}

Voronov, Yu.P., Cand. Sci. (Econ.), Institute of Economics and Industrial Engineering, SB RAS, Novosibirsk

\section{Without Guesswork on Retirement}

Abstract. The article discusses the prospects of using foreign experience of lifelong employment in Russia. Its Japanese and European variants are analyzed for example. It is noted that life-long employment exists in a certain favorable environment, involving, in particular, a large retirement benefit, accounting for the appointment of wages of the employee's dependants, the adoption of all new employees on the same wage. In view of the changes that have taken place since the author's first publication on the subject (see ECO No. 3/2011), he concludes 
that the introduction of full-time life-long employment in Russia is not currently appropriate, but some elements seem to be appropriate. In particular, it is possible and even desirable to introduce lifelong recruitment for certain categories of teachers of Russian universities.

Among other things, this can reduce social tensions over raising the retirement age, as a part of employees and companies will be attracted to a system of lifelong employment. According to the author, it is necessary to change the role of the Pension Fund of Russia, excluding from its competence the appointment, calculation and payment of pensions to civil servants.

Keywords: pension fund; state treasury; lifetime employment; Japanese experience; European experience; education system; government corporations; railways; the hiring of new employees; benefits at retirement

\section{References}

Abegglen, J.C. (2006). 21st century Japanese management: new systems, lasting values. N.Y.: Palgrave Macmillan. Pp. 77-80.

Bodie, Z., Merton, R.C. (2002) International Pension Swaps. Journal of Pension Economics and Finance, March. Pp. 77-83.

Fahey, R. (2018). Japan by the Numbers: Permanent Employment, Tokyo Review, April, 6.

Haak, R. (2005). Japanese Production Management: Organizational Learning at the Confluence of Knowledge Transfer, Technology Development and Work Organization. Japanese management: the search for a new balance between continuity and change / edited by R. Haak and M. Pudelko. N.Y.: Palgrave Macmillan. Pp. 213-237.

Japan: changing the model of economic growth. (1990). Moscow. Nauka Publ. P. 101. (In Russ.).

Karasiuk, E. (2011). Innocence presumption Moscow Re. Sekret firmy. No. 1-2. Pp. 305-306. (In Russ.).

Kavato, A. (2006). Japanese economy: past, present, future. Iaponia siegodnia. Japan today. No. 2. P. 5. (In Russ.).

Kulikov, G.V. (2000). Japanese management and international competitiveness theory. Moscow. P. 144. (In Russ.).

Mironova, T.K. (2018). Pensions for years of service and their social and legal assessment from the standpoint of branch science and constitutional justice. Matters of Russian and International Law. Vol. 8, Is. 8A. Pp. 103-113. (In Russ.).

Morita, A. (2005). Made in Japan. Moscow. Alpina books Publ. P. 133. (In Russ.).

Voronov, Yu.P., Turin, A.O. (2011). Is it possible in Russia to hire for life? ECO. No. 3. P. 92-102. (In Russ.).

Zhuravlev, P.V., Kulapov, M. N., Suharev, S.A. (2007). World experience in personnel management. Review of foreign sources, Ekaterinburg, Delovaya kniga. (In Russ.).

For citation: Voronov, Yu. P. (2019). Without Guesswork on Retirement. ECO. No. 11. Pp. 116-131. (In Russ.). DOI: 10.30680/ECO0131-7652-2019-11-116-131. 